\title{
Design of axle housing bolted joint by analytical method
}

\author{
Chetan D. Papat, Idris Poonawala, S.M.Gaikwad \\ Mechanical Department, Pune University.
}

\begin{abstract}
Front axle is one of the most critical aggregate of the Tractor. It is critical from the Design standpoint since it endures the most severe load condition in the Tractor. The objective of the study is to analyze the design of the axle housing bolted joint of the front axle for service load conditions. During the redesign the axle housing the bolted joint has been changed therefore we need to analyze the bolted of the axle housing. Improvement of the joint of the axle is a major area to address the large failure rate of the sealing in the paddy land application. The bolted joint connections require proper attention and detailed analysis at the design stage for a fail safe operation in service. The various Empirical formulas are used for design and analysis of bolted joint.
\end{abstract}

Keywords: Axle housing,Bolted joint, Tensileload, Slip factor or Coefficient of friction.

\section{Introduction}

Present off-highway vehicle market demands products with low initial and running cost with high productivity to meet the ever growing demand. This in turn gives rise to the more effective use of materials which can reduce the overall weight and ultimately cost and enhance the utility of the vehicle for various applications. In the tractor application the structural component are subjected to low frequency high amplitude loads which cause sudden fatigue failures. Such failure modes are unpredictable and do not give prior indication of failure.

The main purpose of the project is to analyze the existing design of the tractor front axle for service load conditions and redesign the axle by keeping the loadconditions the same. The existing geometry of the front axle is modified to the optimum size which suits for functional requirements with increased life. In this analysis, the geometry of the front axle is modified and a new design is proposed. The objective of this study is to optimize the current design this can be achieved by switching to modular design i.e. from a Monolathic design to a Bilathic design, as a result the weight of the axle is reduced resulting in better performance of the tractor. Finite element simulation is carried out for the existing front axle. The critical location identified and redesigned to ensure life goals are met for the structural components.

In this analysis, the new design is proposed with reduced weight by switching to modular design to improve performance which helps in standardizing parts, reducing design and testing time. We optimized the design of the axle by converting the monolithic design to bilathic design i.e converting the single piece design housing into a two piece design. This will eliminate the carrier assembly reducing the axle weight in turn cost.

In monolithic design the bolted joint between housing and carrier assembly is having less contact pressure at area where the housing has varying thickness, because of less thickness we can't give a bolted joint in that area. In a front axle the forces are applied through the rear and front trunnions and transmitted through the bolted joint between the carrier and housing, these forces give rise to a contact opening at the bolted joint which leads to an oil leak. The unsymmetrical Design of the carrier and housing joint limits the use of ' $O$ '. Ring for sealing. In the bilathic design carrier has been eliminated \& axle housing is divided into two parts. The two parts are assembled using bolts. In this paper we will design the axle housing bolted joint. The objective of the paper is to analyze the design of the axle housing bolted joint of the front axle for service load conditions.

\section{Literature Survey}

[1] Integrated Systems Research, the writer carried out the research on the bolted joint separation due to the eccentric load on the joint. Such joint behavior increases the potential for bolt fatigue. This paper brief addresses the behavior of the eccentrically loaded bolted joint by evaluating the relative benefits that various joint features having on increasing the resistance to separation.

[2] Raju Sethuraman and T. Sasi Kumar, the objective of this paper was to evaluation of the member stiffness. In this paper the wide ranges of bolt sizes, joint thicknesses, and material properties are considered in the analysis to evaluate characteristic behavior of member stiffness. Empirical formulas for the member stiffness evaluation are proposed using dimensionless parameters. The proposed empirical formulas fit very well with the finite element simulations and the maximum deviation observed was less than $3 \%$.

[3] M. Carrera, the objective of this paper was to development the numerical technique for the static analysis of preloaded bolted joints by the FEM using the software ABAQUS Standard and a mesh modeling 
with solid type elements. This technique has been applied to analysis of the bolted joint assembling the longitudinal beams of a new design of modular semitrailer. During analysis it has been found that the Von mises stress reached at the flanges and at several bolt studs. He suggested some modifications to reduce the stress.

Material use for axle housing,

\section{Material}

Material specification ductile iron as per grade SAE D45012 with the following mechanical property,

Hardness: - 156-217 BHN

Tensile strength: - $450 \mathrm{~N} / \mathrm{mm}^{2}$

Yield Strength:- $310 \mathrm{~N} / \mathrm{mm}^{2}$

Elongation in \%:- 12

\section{Material use for bolt,}

The bolt is used 10.9 grades, with the following mechanical property,

Tensile strength:- $940 \mathrm{~N} / \mathrm{mm}^{2}$

Minimum proof strength:- $830 \mathrm{~N} / \mathrm{mm}^{2}$

Minimum yield strength:- $940 \mathrm{~N} / \mathrm{mm}^{2}$

\section{Tensile load on all the bolt of the trumpet joint:-}

\section{Methodology}

The forces on the bolted joint can come in two directions depending on the external load or forces applied on the joint. If the load or forces are applied parallel to the axis of the bolt the joint is said to be the loaded in tension. If the load or forces are perpendicular to the axis of the bolt the joint is said to be the loaded in shear. In tensile joints, the bolts should clamp the joint members together with enough force to prevent them from separating or leaking. The axial load attempts to pull the joint apart. If this load exceeds the bolt yield limit they will stretch the bolt beyond its elastic range causing the bolt to deform permanently and the original preload cannot be regained when the external load removed. Similarly when the external load on the joint exceeds its ultimate tensile strength the bolt will fracture. The relation between the load carried by the joint and bolt due to external loading is referred form the Integrated Systems Research paper [1] and it is given below,

$$
\mathrm{Pi}=\mathrm{Fi}+\mathrm{Pti} * \mathrm{Kr}
$$

Where,

$$
\begin{aligned}
& \mathrm{Pi}=\text { Total tensile load on the bolt } \\
& \mathrm{Fi}=\text { Preload of bolt } \\
& \mathrm{Pti}=\text { Tensile load on the bolt due to external load } \\
& \mathrm{Kr}=\text { stiffness ratio }
\end{aligned}
$$

First let's calculate the stiffness ratio, The principle upon which the stiffness is obtained in the bolt is based on the hooke's law. It assumes that the stresses are within the elastic limit and obey the Hooke's law,

Where,

$$
\mathrm{Kb}=\mathrm{Ab} * \frac{\mathrm{Eb}}{\mathrm{L}} .
$$

$$
\begin{aligned}
& \mathrm{Kb}=\text { Stiffness of the bolt } \\
& \mathrm{Ab}=\text { Area of the bolt } \\
& \mathrm{L}=\text { thickness of the joint } \\
& \mathrm{Eb}=\text { Young modulus of bolt material }
\end{aligned}
$$

We have taken the M10*1.5 bolt type \& from the standard,

\begin{tabular}{|l|l|}
\hline Screw root diameter & $8.14 \mathrm{~mm}$ \\
\hline Ultimate strength & $940 \mathrm{~N} / \mathrm{mm}^{2}$ \\
\hline Mean screw diameter & $9.85 \mathrm{~mm}$ \\
\hline Nominal screw diameter & $10 \mathrm{~mm}$ \\
\hline Screw preload & $36900 \mathrm{~N}$ \\
\hline Screw Young modulus & $210000 \mathrm{~N} / \mathrm{mm}^{2}$ \\
\hline Cast Iron Flange thickness & $15 \mathrm{~mm}$ \\
\hline
\end{tabular}

Table 1 Mechanical properties of bolt material.

For the area of the bolt we can find out using following formula,

$$
\begin{aligned}
\mathrm{Ab} & =\frac{\pi}{4} * \mathrm{D}^{2} \\
& =\frac{\pi}{4} * 8.14^{2}
\end{aligned}
$$




$$
=52.04 \mathrm{~mm}^{2}
$$

Substitute the area of the bolt in equation 1.1, Young modulus \& thickness of the joint i.e flange thickness we calculate the stiffness of the bolt,

$$
\begin{aligned}
& =52.04 * \frac{210000}{15} \\
& =728,560 \mathrm{~N}-\mathrm{mm}
\end{aligned}
$$

Now let's calculate the stiffness of the joint members. Both of the stiffness must be known in order to learn what happens when the assembly joint is subjected to external tensile loading.

$$
\mathrm{Km}=\mathrm{Am} * \frac{\mathrm{Em}}{\mathrm{L}}
$$

Where,

$$
\begin{aligned}
& \mathrm{Km}=\text { Stiffness of the housing } \\
& \mathrm{Am}=\text { Area of the housing } \\
& \mathrm{L}=\text { thickness of the joint } \\
& \mathrm{Em}=\text { Young modulus of housing material }
\end{aligned}
$$

First find the area of the member,

\begin{tabular}{|l|l|}
\hline Nominal screw diameter & $10 \mathrm{~mm}$ \\
\hline Thru Hole diameter & $11 \mathrm{~mm}$ \\
\hline Ext. Flange diameter & $221 \mathrm{~mm}$ \\
\hline Distance between screw centres & $197.99 \mathrm{~mm}$ \\
\hline Cast Iron Young modulus & $170000 \mathrm{~N} / \mathrm{mm}^{2}$ \\
\hline Cast Iron Flange thickness & $15 \mathrm{~mm}$ \\
\hline
\end{tabular}

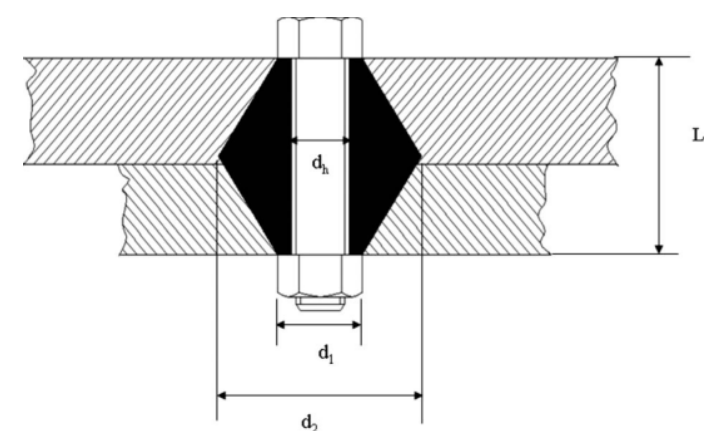

Table 2 Mechanical properties of axle housing material.Figure 1.Schematic of a bolted joint with conical assumption of the clamp zone

Assume $\alpha$ to be $30^{\circ}$. Juvinall and Marshek proposed the following expression to estimate the effective clamping area, Am of the member \& also the housing material is SG iron 450/12 grade,

$$
\mathrm{Am}=\frac{\pi}{4} *\left(\frac{\mathrm{d} 2+\mathrm{d} 1}{2}\right)^{2}-(\mathrm{dh})^{2}
$$

Where, $\mathrm{dh}=\mathrm{d} \& \mathrm{~d} 1=1.5 \mathrm{~d}$

$$
\begin{aligned}
& \mathrm{Am}=\frac{\pi}{4} *\left(\frac{(221-197.99)+(10 * 1.54)}{\mathrm{Am}^{2}}\right)^{2}-(11)^{2} \\
& \mathrm{Am} .64 \mathrm{~mm}^{2}
\end{aligned}
$$

Substitute the area of the member in equation 1.2 and calculating the stiffness of the member joint is,

$$
\begin{aligned}
& =197.64 * \frac{170000}{15} \\
& =2,239,920 \mathrm{~N}-\mathrm{mm}
\end{aligned}
$$

The ratio of the stiffness is calculating by using following formula,

$$
\text { Ratio of stiffness } \begin{aligned}
(\mathrm{Kr}) & =\frac{\mathrm{Kb}}{\mathrm{Kb}+\mathrm{Kc}} \ldots \ldots \ldots \ldots \ldots . \\
& =\frac{728560}{728560+2239920} \\
& =0.2454
\end{aligned}
$$

Now let's calculate the external tensile load on the each bolt. The two axle housing which are joined by means of sixteen bolts and subjected to an eccentric load. Due to the eccentric load the moment (Pe) tend to cause the axle housing to tilt along the edge 'e'. Since the tendency of the axle housing assembly is to tilt about edge 'e'. The strain is proportional to the stretch and the stress is proportional to the strain. Therefore, the resisting force is proportional to the distance of the bolt from the edge ' $\mathrm{e}$ '. The procedure to calculating tensile load is refereed from the V.B Bhandari book [4], Calculating the tensile load by using following formula.

Where,

$$
(\mathrm{Pti})=\frac{\mathrm{Pe} * \mathrm{~L}_{\mathrm{i}}}{\mathrm{L}_{1}^{2}+\mathrm{L}_{2}^{2}+\mathrm{L}_{3}^{2}+\mathrm{L}_{4}^{2}+\cdots \ldots \ldots+\mathrm{L}_{16}^{2}} .
$$

Pti $=$ Tensile load on the bolt due to external load

$\mathrm{Pe}=$ Bending Moment

$\mathrm{Li}=$ distance between the each bolt hole center to the tilting edge ' $\mathrm{e}$ '

First let's calculate the moment, the vertical and horizontal forces are acting on the axle and while designing we consider the resultant forces as given below,

Resultant forces $=\sqrt{(\text { Vertical forces })^{2}+(\text { Horizontal forces })^{2}}$

$$
=\sqrt{(13800)^{2}+(9660)^{2}}
$$




$$
=16,845.04 \mathrm{~N}
$$

The resultant force is acting on the axle at distance of $517.5 \mathrm{~mm}$. So the moment is, Moment $(\mathrm{Pe})=$ resultant load $*$ Load distance from flanges

$$
\begin{aligned}
& =16845.04 * 517.5 \\
& =8,401,089.82 \mathrm{~N}-\mathrm{mm}
\end{aligned}
$$

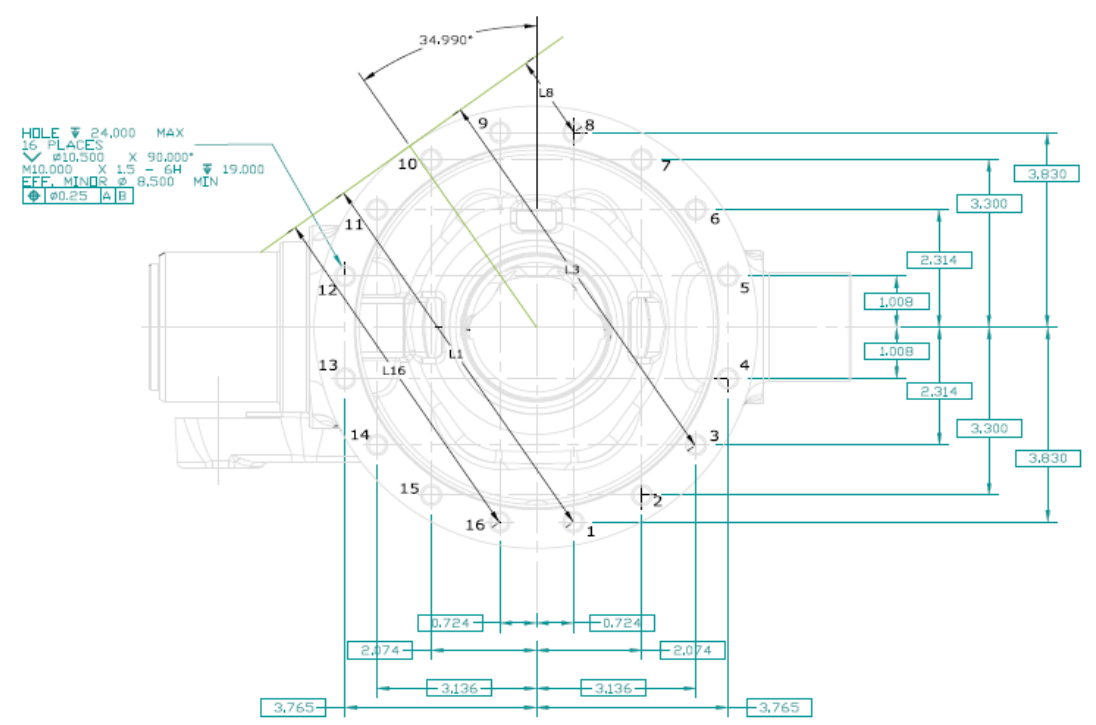

Figure 2.Schematic diagram of a tilting edge of bolted joint in forward direction

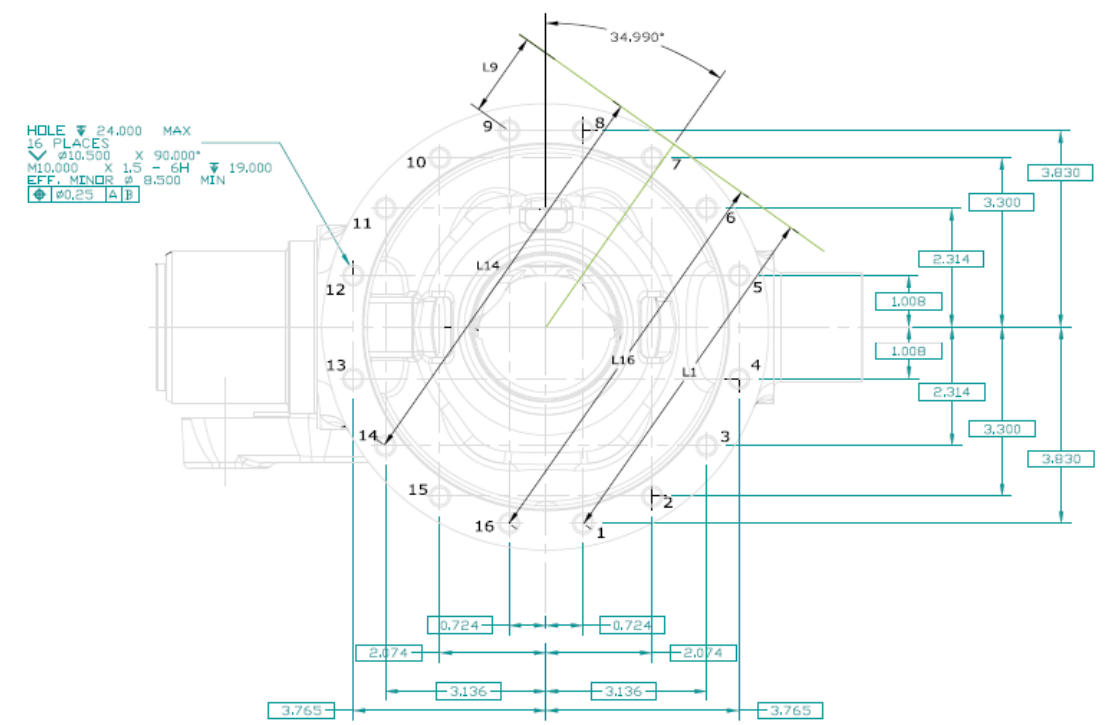

Figure 3.Schematic diagram of a tilting edge ofbolted joint in reverse direction

The figure 1and 2 shows the overall dimension of the bolted joint and also the distance between the each bolt hole center to the tilting edge. Now let's calculate the distance between the each bolt hole center to the tilting edge. We know the position of the bolt hole centers \& using the equation of the line,

$$
\mathrm{Y}=\mathrm{mx}+\mathrm{c}
$$

The slope (m) of the line is calculated \& intercept (c) can be found

$$
\begin{aligned}
& \cos 34.99=\frac{\mathrm{R}}{\mathrm{C}} \\
& \mathrm{C}=\frac{167.64 / 2}{\cos 34.99} \\
& \mathrm{C}=102.32 \mathrm{~mm}
\end{aligned}
$$

Using the formula for finding the distance between line \& the point we can calculate the distance between the each bolt hole center to the tilting edge,

$$
\text { Distance }(1)=\frac{|y-m x-c|}{\sqrt{m 2+1}}
$$


Substituting the equation value of 1.3 and 1.4in equation 1 we can calculate the resultant tensile load on the bolt and the allowable tensile load can be calculated by using following formula,

Yield load of the bolt $=$ Ultimate strength $*$ Area

$$
\begin{aligned}
& =0.9 * 940 * \frac{\pi}{4} * 8.142 \\
& =48,709.6 \mathrm{~N}
\end{aligned}
$$

\section{Find the slip factor or Coefficient of friction,}

During the design of the bolted joint the friction on the surfaces of the clamped package are of great importance. It is taken into account by a slip factor or friction coefficient. Slip Factor is the coefficient of friction on the mating surfaces. These factors vary depending on the type of surface finishing as well as the steel grade of the clamped surfaces in a friction connection. While the slip factor is defined as the slip load divided by the clamping force the maximum permitted slip of 0,15 . If the joint is also exposed to some shear loads, the bolts must also prevent the joint members from slipping.

The coefficient of friction $(\mu \mathrm{i})=\frac{\text { Resultant tensile load }}{\text { Tensile load on the flange }}$

First let's find the resultant tensile load. The formula for the resultant tensile load is given below,

$\operatorname{Pr}=\frac{1}{2} *\left(\mathrm{Pti}+\sqrt{\mathrm{Pt}_{\mathrm{i}}^{2}+4 \mathrm{Ps}_{\mathrm{i}}^{2}}\right)$

Where,

$\operatorname{Pr}=$ Resultant tensile load

Pti $=$ Tensile load on the bolt due to external load

Psi $=$ Shear load on the bolt

Previously we have calculated the tensile load on the bolt equation no 1.4. Now we will calculate the shear load on the bolt. In the shear load there are two shear load first is the primary shear load \& second is secondary shear load.

Primary shear forces $\left(\mathrm{P}_{1}^{\prime}, \mathrm{P}_{2}^{\prime}, \ldots \ldots . \mathrm{P}_{16}^{\prime}\right)=\frac{\text { Resultant forces }}{\text { No of bolts }}$

We know the resultant forces and the no of bolt is 16 so we can find the primary shear forces. Due to the horizontal force the moment $(\mathrm{Pe})$ about the center of gravity result in the secondary shear forces $\mathrm{P}_{1}^{\prime \prime}, \mathrm{P}_{2}^{\prime \prime}, \mathrm{P}_{3}^{\prime \prime}, \mathrm{P}_{4}^{\prime \prime}, \ldots \ldots \ldots \ldots \ldots \ldots . . . . . . . . . . .16$.

$\mathrm{P}_{\mathrm{i}}^{\prime \prime}=\frac{\mathrm{Pe} * \mathrm{R}_{\mathrm{i}}}{\mathrm{R}_{1+}^{2} \mathrm{R}_{2+}^{2} \mathrm{R}_{3+}^{2} \mathrm{R}_{4}^{2}+\cdots \ldots \ldots \ldots \ldots \ldots+\mathrm{R}_{16}^{2}}$

Where,

$\mathrm{P}_{\mathrm{i}}^{\prime \prime}=$ Secondary shear forces

$\mathrm{Ri}=$ radius

$\mathrm{Pe}=$ moment due to the horizontal force

$\mathrm{Pe}=9660 * 113.7$

$=1,098,342 \mathrm{~N}-\mathrm{mm}$

The primary and secondary shear force are added to get the resultant shear forces Psi,

Resultant shear forces $(\mathrm{Psi})=\sqrt{\left(\left(\mathrm{P}_{\mathrm{i}}^{\prime}+\mathrm{P}_{\mathrm{i}}^{\prime \prime}\right) * \cos \theta\right)^{2}+\left(\mathrm{P}_{\mathrm{i}}^{\prime \prime} * \sin \theta\right)^{2}}$

Where,

$\mathrm{P}_{\mathrm{i}}^{\prime}=$ Primary shear forces

$\mathrm{P}_{\mathrm{i}}^{\prime \prime}=$ Secondary shear forces

$\theta=$ Angle between primary and secondary shear forces

Now we will find the tensile load on the flange i.e on the housing.

$$
\mathrm{Pmi}=(\mathrm{Fi})-\operatorname{Pr} *(1-\mathrm{Kr})
$$

Where,

$$
\begin{aligned}
& \mathrm{Pmi}=\text { Tensile load on the flange } \\
& \mathrm{Fi}=\text { Preload of bolt } \\
& \mathrm{Pr}=\text { Resultant tensile load on the bolt } \\
& \mathrm{Kr}=\text { stiffness ratio }
\end{aligned}
$$

Substituting the equation value of 3.1 and 3.2in equation 3 we can calculate the coefficient of the friction or slip factor for each bolt \& final we find the average slip factor and it should be less than the 0.15 then the design is safe. If the slip factor is greater than the 0.15 then we need to increase the no of bolt.

Where,

$$
(\mu)=\frac{\mu_{1}+\mu_{2}+\mu_{3}+\mu_{4}+\cdots \ldots \ldots \ldots \ldots \ldots \ldots+\mu_{16}}{\text { Total no of bolt }}
$$

$\mu=$ Mean coefficient of friction or slip factor 


\section{Result And Discussion}

The calculated tensile load on the bolt, flange contact forces \& coefficient of friction for forward as well as reverse direction are as follows. In forward direction the horizontal force is taken positive and in reverse the horizontal force is negative.

\begin{tabular}{|l|c|r|r|}
\hline $\begin{array}{l}\text { Bolt } \\
\text { No }\end{array}$ & $\begin{array}{l}\text { Total tensile } \\
\text { load on the } \\
\text { bolt }(\mathrm{N})\end{array}$ & $\begin{array}{l}\text { Flange Contact } \\
\text { Force (N) }\end{array}$ & $\begin{array}{l}\text { coefficient of } \\
\text { friction }\end{array}$ \\
\hline 1 & 37285.64 & 30925.14 & 0.21 \\
\hline 2 & 37336.61 & 30702.64 & 0.22 \\
\hline 3 & 37306.85 & 30832.57 & 0.21 \\
\hline 4 & 37200.45 & 31296.96 & 0.19 \\
\hline 5 & 36952.65 & 32378.50 & 0.14 \\
\hline 6 & 36738.05 & 33315.16 & 0.11 \\
\hline 7 & 36525.47 & 34243.00 & 0.07 \\
\hline 8 & 36344.30 & 35033.72 & 0.05 \\
\hline 9 & 36219.61 & 35577.94 & 0.03 \\
\hline 10 & 36168.64 & 35800.40 & 0.03 \\
\hline 11 & 36198.43 & 35670.40 & 0.03 \\
\hline 12 & 36304.84 & 35205.93 & 0.04 \\
\hline 13 & 36552.64 & 34124.38 & 0.08 \\
\hline 14 & 36767.22 & 33187.82 & 0.11 \\
\hline 15 & 36979.79 & 32260.05 & 0.15 \\
\hline 16 & 37160.95 & 31469.36 & 0.18 \\
\hline
\end{tabular}

Table 3 Tensile load, Flange contact forces and coefficient of friction of each bolt for forward direction

\begin{tabular}{|c|c|c|c|}
\hline Bolt No & $\begin{array}{r}\text { Total tensile } \\
\text { load on the bolt } \\
(\mathrm{N})\end{array}$ & $\begin{array}{r}\text { Flange } \\
\text { Contact } \\
\text { Force }(\mathrm{N})\end{array}$ & $\begin{array}{l}\text { coefficient } \\
\text { of friction }\end{array}$ \\
\hline 1 & 37160.92 & 31469.50 & 0.18 \\
\hline 2 & 36979.77 & 32260.16 & 0.15 \\
\hline 3 & 36767.20 & 33187.92 & 0.11 \\
\hline 4 & 36552.62 & 34124.49 & 0.08 \\
\hline 5 & 36304.84 & 35205.95 & 0.04 \\
\hline 6 & 36198.45 & 35670.29 & 0.03 \\
\hline 7 & 36168.69 & 35800.21 & 0.03 \\
\hline 8 & 36219.66 & 35577.73 & 0.03 \\
\hline 9 & 36344.34 & 35033.56 & 0.05 \\
\hline 10 & 36525.48 & 34242.93 & 0.07 \\
\hline 11 & 36738.03 & 33315.24 & 0.11 \\
\hline 12 & 36952.59 & 32378.76 & 0.14 \\
\hline 13 & 37200.37 & 31297.30 & 0.19 \\
\hline 14 & 37306.78 & 30832.87 & 0.21 \\
\hline 15 & 37336.56 & 30702.88 & 0.22 \\
\hline 16 & 37285.59 & 30925.33 & 0.21 \\
\hline
\end{tabular}

Table 4 Tensile load, Flange contact forces and direction

In the forward direction the horizontal forces is positive and the tilting edge lies in the fourth quadrant because of which the distance of the tilting edge from bolt no 2 is the farthest. Therefore the tensile load on the bolt no 2 is maximum. Subsequently the coefficient of the friction is also maximum for bolt no 2 .

Mean coefficient of friction in forward direction $=\frac{\mu_{1}+\mu_{2}+\mu_{3}+\mu_{4}+\cdots \ldots \ldots \ldots \ldots \ldots \ldots \ldots+\mu_{16}}{\text { Total no of bolt }}$

$=\frac{1.98}{16}$

$=0.12$

Mean coefficient of friction in reverse direction $=\frac{\mu_{1}+\mu_{2}+\mu_{3}+\mu_{4}+\cdots \ldots \ldots \ldots \ldots \ldots \ldots . .+\mu_{16}}{\text { Total no of bolt }}$

$=\frac{1.98}{16}$

$=0.12$

In the reverse direction the horizontal forces is negative and the tilting edge lies in the first quadrant because of which the distance of the tilting edge from bolt no 15 is maximum. Therefore the tensile load on the bolt no 2 is maximum. Subsequently the coefficient of the friction is also maximum for bolt no 15 .

\section{Conclusion}

In the forward condition the maximum tensile load is $37336.61 \mathrm{~N}$ and for the reverse condition the maximum tensile load is $37336.56 \mathrm{~N}$. The allowable tensile load is $48,709.6 \mathrm{~N}$. Maximum tensile load is less than the allowable tensile load so design is safe. The average slip factor for the forward and reverse is 0.12 which is to be less than the 0.15 therefore the design is safe.

\section{Reference}

[1] Optimizing Bolted Joint Geometry for Fatigue Resistance by Integrated Systems Research

[2] Finite Element Based Member Stiffness Evaluation of Axisymmetric Bolted Joints by Raju Sethuraman and T. Sasi Kumar

[3] Development of a Numerical Technique for the Static Analysis of Bolted Joints by the FEM by D. Valladares, M.Carrera, L. Castejon, C. Martin

[4] Design of Machine Elements by V.B Bhandari.

[5] Mechanical Engineering Design, 4th Edition, Shigley and Mitchell, McGraw Hill 